\title{
Revisiting core issues in dynamic assessment
}

\author{
Raegan Murphy \\ Department of Applied Psychology, University College Cork, Cork, Ireland \\ raegan.murphy@ucc.ie \\ D.J.F. Maree \\ Department of Psychology, University of Pretoria, Pretoria, South Africa
}

Dynamic assessment is currently poised at a juncture where theoretical and practical assessment resolutions are necessitated. Such issues concern theoretical approaches towards psycho-educational assessment. In order to partially explore these basic assessment approaches, a questionnaire was delivered via electronic mail to 100 international, currently active, dynamic assessment researchers and practitioners. The findings from the responses formed the basis for an informal content analysis, which was conducted utilising themes as primary meaning unit and word counts as secondary meaning unit of analyses. The one common and uniting feature about the current research in this area is the broad range of theoretical approaches towards assessment and the current lack of unanimity across types of approaches. Responses showed that varied theoretical frameworks are employed in dynamic assessments which do not necessarily cohere with other traditional approaches. It is contended that an exploratory revisiting of core assessment approaches would assist in positioning practitioners' and researchers' theoretical approaches in future assessments.

Keywords: assessment approaches; content analysis; dynamic assessment; questionnaires; theory; underpinning

Dynamic assessment provides the psycho-educational practitioner an opportunity to engage with an individual in an assessment situation in a manner quite dissimilar from the traditional mode of assessment. It has an almost intuitive appeal for educators and assessors alike. However, due to a number of reasons this method of assessment is not as widely practised as it could be. Apart from the typical at-times impracticalities of conducting dynamic assessments, it may well be that there are a number of core issues that need to be investigated before more advice can be offered as to why this manner of assessment is not more widely practised.

\section{A BRIEF OVERVIEW OF DYNAMIC ASSESSMENT}

Dynamic assessment is a manner of assessing individuals' at times hidden potential or reserve capacity in a fluid, process-orientated, diagnostic, engaged and flexible manner in which aiding or guidance via instruction and feedback of cognitive skill acquisition is of prime importance (Campbell \& Carlson, 1995; Elliott, 2003; Gillam \& McFadden, 1994; Grigorenko \& Sternberg, 1998; Kirkwood, Weiler, Bernstein, Forbes, \& Waber, 2001; Kirschenbaum, 1998; Kliegl, Smith, \& Baltes, 1989; Lidz, 1992a, Lidz, 1997; Meyers, 1987; Minick, 1987; Sternberg \& Grigorenko, 2002). It stands in stark contrast to the more product-bound approaches of mainstream psychometric and edumetric assessment (Craig, 1991; Gupta \& Coxhead, 1988b; Resing, 1993; Slenders \& Resing, 1997) by emphasising the change in performance (rate) and remedial strategies necessary to progress (Bejar, 1984; Brown \& French, 1979; Campione, 1989; Wied1, 2003). Rate of learning, amount of improvement (typical of the Feuersteinian and neo-Vygotskian views) as well as amount of aid necessitated (more modern views of gauging potential) are all methods of assessing for growth of learning or potential (Ferrara, Brown, \& Campione, 1986).

The relationship between tester and testee as characteristic of strict neutrality is the hallmark of conventional testing which, if violated, would render the objectivity null and void (Greenfield, 1997) but not so with dynamic assessment (Lidz, 1992b). It represents greater all round diversity in 
assessment and the method's results extrapolate to a far wider field of application than mainstream assessment (Gupta \& Coxhead, 1988a) leading to, at times, fairer and greater predictive diagnostic validity (Ferrara, Brown, \& Campione, 1986; Gredler, 1988; Resing, 1997) for below-average performers (both majority and minority groupings) on conventional IQ tests (Babad \& Budoff, 1974; Budoff \& Hamilton, 1976; Hessels, 1996).

Movements are afoot within static-based modes of testing which seek to make such tests more functional, at least for special education populations in terms of prescribing treatment in respect of test results yielding another type of validity, that of treatment validity (Flanagan, Andrews, \& Genshaft, 1997). Its basic philosophy advocates that individuals are continuously changing throughout life and developing expertise (Sternberg \& Grigorenko, 2002). As holistic beings, contextual factors as opposed to genetic factors are perhaps more emphasized as playing a greater role in how individuals cope in life and also how they cope within assessment situations even though heritability cannot be ignored (Das, 1987; Guthke, 1993). Research within dynamic assessment typically has as a research design a pretest-mediation-posttest model (Budoff, 1987; Campione, 1996; Elkonin, Foxcroft, Roodt, \& Astbury, 2001; Hamers \& Resing, 1993; Lidz, 1987; Lidz \& Pena, 1996). There are variations on this design ranging from purely clinical interventions (Sternberg, 2000) such as those offered by Feuerstein and Jensen (Feuerstein, Feuerstein, Falik, \& Rand, 2002; Jensen, 2000) to more robust standardized interventions offered by Budoff and Campione for instance (Budoff, 1987; Campione \& Brown, 1987).

Dynamic assessment as a method of testing is uniquely placed in South Africa as the majority of learners in this country have suffered moderate to severe educational handicaps due to past segregationist policies, the results of which are still prevalent (Skuy et al., 2002). As such, dynamic assessment is considered a method less biased towards the socially disenfranchised (Elliott, 2000) and hence more suitable as a viable alternative to current psychometric tests (Hessels \& Hamers, 1993; Sewell, 1987; Van de Vijver, 1993). Gains in scores between pretest and posttest South African dynamic assessment interventions have evidenced that, in general, dynamic assessment has proved efficacious as a method of helping individuals improve on tasks requiring skills in varying test batteries (Murphy, 2002; 2007; Murphy \& Maree, 2006a; 2006b).

A number of South African studies citing the influential works of the founding figures in dynamic assessment have appeared over the years in this journal (Ahmed \& Pillay, 2004; De Beer, 2005; Craig, 2000, Herbst \& Huysamen, 2000, Murphy \& Maree, 2006a; Norris \& Foxcroft, 1996; Taylor, 1994). Binet, Vygotsky, and Feuerstein are considered to be originators in this approach with focus on Vygotskian theory as applicable to diverse populations in western and non-western psychology (Murphy, 2008). Due to applicability of dynamic assessment as an approach to psychoeducation in South Africa and the wider community, the question remains why this manner of assessment has yet to make strides within current practice. A number of publicised findings have yielded possible reasons why this may be the case.

\section{Issues within dynamic assessment}

Four surveys, conducted within the United States, United Kingdom and Ireland evidence similar results in terms of the recognition of dynamic assessment as manner of assessment as well as the utilisation of this method within practice (Deutsch \& Reynolds, 2000; Haney \& Evans, 1999; Lidz, 1992a; Raftery \& Murphy, 2009). Findings conclude that although there is varying awareness of dynamic assessment it is practiced less often. Dynamic assessment is currently poised at a juncture at which theoretical and practical assessment resolutions are necessitated. Such issues concern theoretical approaches towards psycho-educational assessment. The one common and uniting feature about the current research in this area is the broad range of theoretical approaches towards assessment and the current lack of unanimity across types of approaches. It is contended that an exploratory revisiting of core assessment approaches would assist in positioning practitioners' and researchers' theoretical approaches in future assessments. 
To this end the development of a questionnaire was partly motivated by the statements made by Greenberg (2000) about dynamic assessment and the needs highlighted earlier:

- Various models and theories need to be understood before the embarkation into dynamic assessment.

- The devices available need to be understood in terms of their workings.

- Dynamic assessment is inherently a loose set of tailored approaches and depending on the context and person being assessed needs to reflect this individuality of assessment.

- The need to link up dynamic assessment with classroom intervention poses a particular problem as there is usually a lack of human and financial resources.

- Dynamic assessment should include as an inherent feature of its approach assessment and intervention.

- What makes the situation dynamic is the dynamic adaptability of the assessment to the person.

- The tasks involved in assessments should reflect the interests of the client and should take place in a relaxed atmosphere.

- People themselves are dynamic beings and both process and product should be assessed.

- Due to its malleable approach towards assessment, dynamic assessment presents with an eclectic array of techniques in its repertoire and hence should not and usually is not bound by certain strategies.

In order to ensure that the questionnaire contained as many of the above ideas as possible, eight questions were devised which placed emphasis on the above concerns.

\section{METHOD}

One hundred questionnaires were emailed to dynamic assessment/learning potential practitioners across the globe. These individuals were identified from the current literature as having either published dynamic assessment test batteries and/or as having published articles within the last five years. Thirty-one individuals responded with the initial intent of completing the questionnaire. Eight practitioners refrained from answering due to lack of time and unfamiliarity with the field. Follow-up e-mails were sent to practitioners who had originally expressed interest in the study. Eleven completed questionnaires were finally returned and the final analysis was conducted on these eleven contributions. As only eleven questionnaires were returned as well as the fact that most responses were quite short (less than five sentences on average per question) a thematic analysis of content response was deemed suitable. Four South African researchers were initially contacted but no completed response was received.

\section{Sample}

Respondents were clinicians in private practice as well as professors and lecturers within schools of psychology, counselling psychology, education, pedagogical psychology, teaching, learning and instruction, learning disabilities, biological psychology as well as psycho-educational consultation and training. Respondents currently teach and/or co-ordinate programmes within tertiary institutions in the United States, Canada, Britain, Israel and the Netherlands and are also involved in private practice consultations.

\section{Questions}

Eight questions were asked of respondents and these are listed in Table 1.

\section{Procedure}

Whitley (2002) states four main steps along which content analysis should proceed which reflects the process of qualitative research in general (Creswell, 2002) namely, the sources of data to be utilised, the sampling of respondents, the development of a coding scheme and the measurement of the content. 
Table 1. Questions

1. The status of your particular view of dynamic assessment within intelligence assessment. What would you consider to be the nature of your view of dynamic assessment? Do you consider it to be a conceptual scheme, model or theory? (taking cognisance of the differences inherent within these various modes of views). Some may consider their views as merely tentative schemes whereas others may perceive their ideas to be fully-fledged theoretical stances hence moulding and structuring their practical endeavours accordingly.

2. Philosophical bent or underpinning of your theoretical take on dynamic assessment. Deeply entrenched within any idea/model/theory or simply a view on life, are allied philosophical understandings of how things ought to work. Whether tacitly supporting this notion or taking a dislike to its deterministic way of looking at the world, makes no difference for the moment. On each of the following views or issues listed below, what are your ideas concerning dynamic assessment within the broader field of intelligence assessment? For instance, based on your views concerning mind/brain, it may be that in downplaying the role of neuroscience, one concentrates on the behavioural level only, thus hypothesising that behaviour is indeed malleable at a level not synonymous with neural architecture (or at any other level). This will of course play out in your fundamental beliefs and hence theory(ies) behind your views on dynamic assessment.

- $\quad$ On nature and nurture: From nativists, empiricists to selectionists (how the brain/mind develops along purely genetic lines to environmental impingements),

- On mind/brain: from Cartesian dualism to succinct mind/brain identity theory,

- On agendas: from pragmatic to Socratic ideas as to the role of your view and the resulting influences in practice and on the 'science' of the field

- On historicity: the direct/indirect (or total lack thereof) impact of historicity within the current understandings within intelligence assessment (how varied and indeed colourful is dynamic assessment's historical and geographical vistas!)

3. Your developmental model followed or model most adhered to within the field of child development/ educational development as well as adult growth and maturation. Which developmental model within child/adult development and maturation do you most closely follow when working within dynamic assessment? For instance, biologically driven theories of development, environmentally aligned theories of development and theories which challenge both extremes by meeting midway are offered as tentative guides as to how you might want to answer this particular question. Any well-known theory may equally be appended with the prefix of "neo" seeing as older theories are or will have to be continually assessed in terms of their fundamentals (neo-Piagetian, neo-Vygotskian, neo-anything you think would be appropriate here). Any inclusive model be it ethologically driven, social-learning theory driven or informationprocessing driven as well as any hybrid theories on the horizon can be utilised to explain your thoughts.

4. The ensconcement of your theoretical take on dynamic assessment within the broader fields of intelligence assessment. Where do you think your view/theory of dynamic assessment should be placed within the broader framework of intelligence assessment? Factors to consider when answering this question include (but is not an exhaustive list, you may add more factors which you find important):

- The intelligence models you most closely follow when placing your dynamic assessment view within it

- Your views concerning dynamic assessment and intelligence; are they divorced from any such particular intelligence model or are they firmly embedded within two or more models?

- Your views concerning dynamic assessment and your chosen model(s) of intelligence: are they linked in any way or do you perceive them to be ill-at-ease conceptually?

- Your views on dynamic assessment and how they fit in within the various competing views of intelligence. Where would you place your views? For instance, you might classify your views as nesting within a psychometric model itself housed within an intelligence model. The tenets inherent within a psychometric view as well as those inherent within your chosen model of intelligence will impinge on your view of dynamic assessment 
Table 1. Continued

5. The affinities your particular theory of dynamic assessment has with aligned fields of neuroscience, neuropsychology and computational intelligence. Current findings in the popular science and psychology literature as well as the increasing findings within academic literature (or at least the reporting of such findings) at times leads one to conclude that this new century could well be cited as the century of the "physical" (brain, genes, proteins, etc.). Keeping this in mind, consider the following:

- How have these fields of enquiry been built into your view/model/theory of dynamic assessment within intelligence research?

- Do you think such findings should/should not play a role in further defining how your view should or should not be adapted? If yes, how do you think this should proceed?

6. The historical development of this sub-field of enquiry and its potential future within the realm of psychology (itself moving towards a more integrated field comprising natural science and behavioural sciences methodologies). Having emanated from a natural philosophical background, allied to the natural sciences, finding favour with various movements within psychology through the century and having traversed a large field of enquiry, psychology and in particular intelligence (and dynamic assessment) is the proud bearer of a rich history, albeit a brief one.

Will dynamic assessment as a movement/model/theory simply die a death due to various factors or, will it in your opinion, forge ahead making strides unbeknownst to practitioners today?

Humans are not terribly successful in determining what will and will not make an impact, even though an impact may not be construed as such for a long time to come. On the other hand, pursuing avenues with no definitive profit in terms of theory development may hinder development in other realms with resources better spent in these other realms.

- What are your thoughts on this matter?

7. The quantitative imperative. The role of statistics within psychology has been questioned and even criticised (the APA's Task Force on Statistical Inference, 1996) and the works of Joel Michell and others give a voice to the critical philosophy of mathematics and measurement within the social sciences. Would this perhaps add fuel to the fire as far as your view on dynamic assessment within intelligence is concerned or would this add support and buffer your views in terms of how dynamic assessment and intelligence should in fact proceed?

8. The meta-theoretical solution or pie in the sky. Some regard meta-theories as too reductionistic and their practitioners as naïve in attempting to simplify too complex an area of research within intelligence research. What potential lies within such an endeavour for dynamic assessment in your opinion? Would it help to stabilise the field or merely contribute towards confusion?

\section{Coding of the content}

We followed Creswell's (1998) general and overall mode of enquiry which is viewed as a spiral of research emphasising the description, classification and interpretation of text. Once the pooled views were grouped under each question a thematic analysis was conducted in order to fully explore underlying themes within the summarised responses. Once the themes had been highlighted we investigated the responses for aspects not mentioned as this is also considered of importance within content analysis. These issues are indicative either of the irrelevance of the topic or the lack of knowledge surrounding the particular issue of concern.

\section{Process}

Themes were utilised as meaning unit and the categories of the coding frame (Berg, 2001) consisted of axes of meaning which would either support an issue or not, or else would be regarded as neutral on an issue. The first three responses to each question were investigated for suitability after which 
the aforementioned axes were routinely applied across the questions except for question 3 which did not avail itself of such coding. The coding of the text proceeded line-by-line (Strauss \& Corbin, 1998) and followed Whitley's (2002) recommendations in terms of the characteristics of coding systems.

\section{RESULTS}

The results contained in this section are the authors' summarised analysis of respondents' results and are not the respondents' verbatim responses to the questions.

\section{Question 1 - The status of dynamic assessment within intelligence assessment}

Dynamic assessment is currently considered as more of a model than a fully-fledged theory and consists of hybridised approaches towards the assessment of the whole individual within varied contexts. There appears to be lack of consensus surrounding its status. It is informed from a variety of implicit assumptions about learnability, the learning experience, the potential to learn and the modifiability of individuals. It undergirds the assessment of cognitive functioning and includes affective and non-cognitive aspects over and above intelligence traits and is seen as relevant in culturally diverse situations where the whole person and context is taken into account and where reality is socially constructed.

A major detraction from this question is the numerous possible contrasting understandings that various researchers and practitioners may have of constructs such as 'paradigm' or 'theory'. Some practitioners view dynamic assessment purely as a convenient measure of potential. There is difficulty in deriving a tool or instrument sufficient and worthy enough to measure something which in some ways defies measurement, as operationalising the concept is problematic. There is, however, empirical evidence to suggest construct validity and this is seen as a tentative beginning to its growth as a method within the scientific discipline of assessment. Table 2 illustrates these trends. Figure 1 illustrates the continuum of increasing conceptualisation and where respondents indicated dynamic assessment could be placed.

Table 2. Dynamic assessment's status as scheme, model or theory

\begin{tabular}{|c|c|c|c|c|c|}
\hline $\begin{array}{l}\text { Mutually exclusive } \\
\text { categories }\end{array}$ & $\begin{array}{l}\text { Frequency } \\
\text { count }\end{array}$ & $\begin{array}{l}\text { Mutually inclusive } \\
\text { categories }\end{array}$ & $\begin{array}{l}\text { Frequency } \\
\text { count }\end{array}$ & $\begin{array}{l}\text { Opposing } \\
\text { view }\end{array}$ & $\begin{array}{l}\text { Frequency } \\
\text { count }\end{array}$ \\
\hline Model & 7 & $\begin{array}{l}\text { Theory/model } \\
\text { hybrid }\end{array}$ & 2 & $\begin{array}{l}\text { Not a } \\
\text { theory }\end{array}$ & 2 \\
\hline Theory & 6 & $\begin{array}{l}\text { Model with concept } \\
\text { as subservient }\end{array}$ & 3 & & \\
\hline $\begin{array}{l}\text { Assessment/proce- } \\
\text { dure/approach }\end{array}$ & 3 & $\begin{array}{l}\text { Model with theory } \\
\text { as subservient }\end{array}$ & 1 & & \\
\hline Concept & 3 & & & & \\
\hline Paradigm & 1 & & & & \\
\hline Philosophical stance & 1 & & & & \\
\hline
\end{tabular}

\section{Question 2 - Theoretical underpinning of dynamic assessment}

Dynamic assessment is firmly anchored in socio-cultural and bio-ecocultural models of a socially constructed reality. It places emphasis on how the environment influences change although cognisance is taken of the increasingly important role of heredity. The processes involved in learning are socially constructed and hence many views of dynamic assessment are rooted in Vygotskian mediation theory. In order for dynamic assessment to become accepted within mainstream intel- 


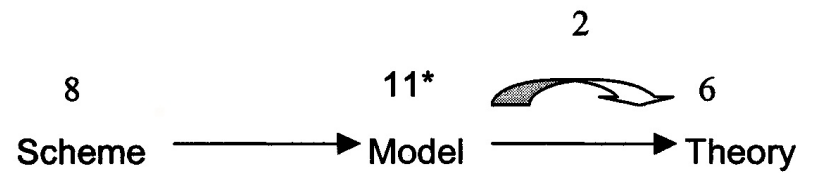

* when including the mutually inclusive category. Seven exclusive mentions

Figure 1. View of dynamic assessment along a continuum of increasing conceptualisation

ligence assessment, if this is where it wishes to lodge itself, it needs to become standardised which is antithetical to the notion underpinning it. Table 3 shows the frequency counts for the responses to this question.

Table 3. Dynamic assessment philosophy

\begin{tabular}{lclc}
\hline Aspect & Frequency count & Aspect & Frequency count \\
\hline Nature & 11 & Nurture & 13 \\
Nature/nurture interaction & 9 & & \\
Mind and brain & 0 & Mind is brain & 1 \\
Pragmatic agenda & 2 & Socratic agenda & 0 \\
Direct role of history & 2 & Indirect role of history & 0 \\
\hline
\end{tabular}

\section{Question 3-Developmental model within the field of child development/educational development as well as adult growth and maturation}

No one particular developmental model is adhered to within dynamic assessment and of those mentioned most are ecologically aligned theories evidencing eclectic influences. Theorists such as Feuerstein, Vygotsky and Piaget are mentioned as being influential in dynamic assessment's progress since inception. Whether a narrowing in scope of chosen developmental models will occur is speculative as best. Multiple theoretical models are utilised as no one specific model encompasses all that is necessary to explain the global functioning of the learner. Hybrid and eclectic models are preferred over-and-above any one particular model.

\section{Question 4 - The theoretical underpinning in dynamic assessment within the} broader field of intelligence assessment

Dynamic assessment makes use of intelligence tests which function in a role considered complementary to current static intelligence tests. Intelligence is an ill-defined notion and as such it is difficult to define is role within dynamic assessment. Dynamic assessment sees itself as encompassing intelligence and not as intelligence encompassing it. Dynamic assessment was therefore not placed within any intelligence theory or model. Intelligence as conventionally understood and measured is not the target of dynamic assessment intervention. The emphasis is on the remediation of problems within cognitive functioning and very often these problems are a culmination of environmental, ecological, socio-cultural, community and family concerns in which the developing child is situated. Adult intervention is also of concern to dynamic assessment. 
Question 5 - The affinities a theory of dynamic assessment has with aligned fields of neuroscience, neuropsychology and computational intelligence

There is fairly wide-spread consensus about the increasingly important role of neuroscience within dynamic assessment and how it may inform the process, but this is tempered by the fact that such consilience will occur later rather than sooner. At present such findings do not play a very prominent role within dynamic assessment. Findings from neuroscience are increasingly playing a major role in psychological literature as it pertains to cognitive functioning.

\section{Question 6-The historical development of this sub-field of enquiry and its potential} future within the realm of psychology

Most practitioners fervently hope that the field of dynamic assessment remains a field of research and also wish for greater acceptance among mainstream assessment. What is perhaps the most implicitly impassioned complaint is the fundamental philosophy underlining dynamic assessment and how this will be lost if the method which it underpins ceases to be practised. Problems with standardisation as well as issues of costs and time seem to mitigate against the further acceptance of the approach within a wider setting and it is ironic that at times those most opposed to the approach are very often psychologists.

\section{Question 7 - The quantitative imperative}

The move away from quantification has stemmed from criticism aimed at standardised methods of assessment which have had some unfortunate consequences for some groups of individuals. Dynamic assessment's predicate of qualitative intervention aimed specifically at change through assessment views quantification as anathema yet a necessary part of the assessment process. Historical relevance in terms of these issues was however not mentioned. Issues of great import to conventional intelligence assessment are simply not considered that important even if relevant to dynamic assessment. The need for empirical verification of educational interventions is stressed. Table 4 illustrates the frequency count of the responses to this question.

Table 4. The role of quantification and measurement within dynamic assessment

\begin{tabular}{lc}
\hline Aspect & Frequency count \\
\hline Measurement is a necessary part of dynamic assessment & 2 \\
Measurement has resulted in dynamic assessment moving away from & 5 \\
its original ideals & \\
\hline
\end{tabular}

\section{Question 8 - The role of metatheory}

Meta-theorising, as understood to be theory about theory within intelligence and dynamic assessment may be fruitful in the long-run. Some consider dynamic assessment as yet too young a field theoretically-speaking and meta-theorising is often a task undertaken after established solid theorising has taken place (Table 5).

Table 5. The role of meta-theory within dynamic assessment

\begin{tabular}{cc}
\hline Aspect & Frequency count \\
\hline Meta-theory will only serve to add confusion to the field & 6 \\
Meta-theory is a welcome addition to this field & 4 \\
\hline
\end{tabular}




\section{DISCUSSION}

The lack of consensus regarding the status of dynamic assessment as theory, model, conceptual scheme, philosophy or even construct brings into question the degree of explanatory power of a theory versus that of a model. Broader based conceptual schemes may encompass more variables and may be lodged within larger spectrums that are unable to explain as clearly issues explicated in more narrowly confined conceptual schemes utilising more accurate terminology.

There was a passing familiarity with the literature emanating from neuroscience studies. This may indicate that neuroscience as a potentially rich source of information is not necessarily the area in which dynamic assessment practitioners should focus attention. Intelligence is understood at its broadest level to play a role of relegated support. No mention was made of the use of item responses theory as measurement theory in helping to abate the increasing flood of criticism levelled at dynamic assessment's lack of robust measurement technique. No mention was made of the basic philosophy underpinning the very need to utilise quantitative measures within psychological assessment. The routes travelled by mainstream intelligence assessment (leaning heavily upon psychometrics and factor analytic statistical foundations emanating from pragmatic American psychology and British empirical psychology) and that of dynamic assessment (leaning towards open-ended change and informed more from continental European considerations of assessments) was not highlighted as playing potential roles in the quantitative debate.

\section{CONCLUSION}

The need to re-visit theoretical underpinnings within various dynamic assessment approaches is timely due, in main, to the lack of established practice within traditional psycho-educational assessment. Eight questions dealing with core issues within dynamic assessment were put forward and content analysis as technique for response analysis was chosen. Main trends within responses were evident and included the predominating model-like status of dynamic assessment and its primary emphasis on contextual factors as major influencing variable in the testing situation. Dynamic assessment is predicated on hybridised and eclectic development models and views intelligence assessment as complementary to its main goal of mediatory intervention strategy.

Practitioners need to be aware that dynamic assessment is an umbrella term containing myriad approaches towards assessment. These approaches are entrenched in certain theoretical views which may not always cohere with the traditional mode of assessment such as static-based assessments. Underpinning theories guide not only the theory of dynamic assessment method but also the practice of interactive assessments. Practitioners may blur various approaches into a unified approach and find that the assessment strategy may not cohere with what is required in practice. There is a measure of vagueness of about what exactly is meant by constructs such as 'paradigm', 'theory', 'model' and 'approach'. There also seems to be a lack of agreement as to what an approach is as opposed to a methodology of assessment. The blurred nature of current practice detracts somewhat from the further use of dynamic assessment as psycho-educational tool. If practitioners are better positioned to understand various theoretical strands within their work, dynamic assessment may yield greater advantages than it currently does.

\section{ACKNOWLEDGEMENT}

We thank the anonymous reviewer for comments.

\section{REFERENCES}

Ahmed, R., \& Pillay,A.L. (2004). Reviewing clinical psychology training in the post-apartheid period: Have we made any progress? South African Journal of Psychology, 34, 630-656.

Babad, E.Y., \& Budoff, M. (1974). Sensitivity and validity of learning-potential measurement in three levels of ability. Journal of Educational Psychology, 66, 439-447.

Bejar, I.I. (1984). Educational diagnostic assessment. Journal of Educational Measurement, 21, 175-189. Berg, B.L. (2001). Qualitative research methods for the social sciences. Massachusetts: Allyn and Bacon. 
Brown, A.L., \& French, L.A. (1979). The zone of potential development: implications for intelligence testing in the year 2000. Intelligence, 3, 255-273.

Budoff, M. (1987). Measures for assessing learning potential. In C.S. Lidz (Ed.), Dynamic assessment: an interactional approach to evaluating learning potential (pp.173-195). New York: Guilford Press.

Budoff, M., \& Hamilton, J.L. (1976). Optimizing test performance of moderately and severely mentally retarded adolescents and adults. American Journal of Mental Deficiency, 81, 49-57.

Campbell, C., \& Carlson, J.S. (1995). The dynamic assessment of mental abilities. In J.S. Carlson (Ed.), European contributions to dynamic assessment Volume 3 (pp.1-31). London: JAI.

Campione, J.C. (1989). Assisted assessment: a taxonomy of approaches and an outline of strengths and weaknesses. Journal of Learning Disabilities, 22, 151-165.

Campione, J.C. (1996). Assisted assessment: a taxonomy of approaches and an outline of strengths and weaknesses. In H. Daniels (Ed.), An introduction to Vygotsky (pp.219-250). London: Routledge.

Campione, J.C., \& Brown, A.L. (1987). Linking dynamic assessment with school achievement. In C.S. Lidz (Ed.), Dynamic assessment: an interactional approach to evaluating learning potential (pp.82-109). New York: Guilford Press.

Craig, A. (1991). Adult cognition and tertiary studies. South African Journal of Higher Education, 5, $137-144$.

Craig, A.P. (2000). Time and Learning. South African Journal of Psychology, 30, 6-16.

Creswell, J.W. (1998). Qualitative inquiry and research design: choosing among five traditions. London: Sage.

Creswell, J.W. (2002). Educational research: planning, conducting, and evaluating quantitative and qualitative research. New Jersey: Merrill Prentice Hall.

Das, J.P. (1987). Forward. In C.S. Lidz (Ed.), Dynamic assessment: an interactional approach to evaluating learning potential (pp.vii-xi). New York: The Guilford Press.

De Beer, M. (2005). Development of the learning potential computerized adaptive test (LPCAT). South African Journal of Psychology, 35, 717-747.

Deutsch, R. M., \& Reynolds, Y. (2000). The use of dynamic assessment by educational psychologists in the UK. Educational Psychology in Practice, 16, 311-331.

Elkonin, D., Foxcroft, C., Roodt, G., \& Astbury, G. (2001). The use of assessment measures in various applied contexts. In C. Foxcroft, \& G. Roodt (Eds), An introduction to psychological assessment in the South African context (pp.265-294). Cape Town: Oxford University Press.

Elliott, J.G. (2000). Dynamic assessment in educational contexts: purpose and promise. In C. Lidz, \& J.G. Elliott (Eds), Dynamic assessment: prevailing models and applications (pp.713-740). New York: Elsevier.

Elliott, J.G. (2003). Dynamic assessment in educational settings: realising potential. Educational Review, $55,15-32)$.

Ferrara, R.A., Brown, A.L., \& Campione, J.C. (1986). Children's learning and transfer of inductive reasoning rules: studies of proximal development. Child Development, 57, 1087-1099.

Feuerstein, R., Feuerstein, R.S., Falik, L.H., \& Rand, Y. (Eds). (2002). The dynamic assessment of cognitive modifiability. Israel: The ICELP Press.

Flanagan, D.P., Andrews, T.J., \& Genshaft, J.L. (1997). The functional utility of intelligence tests with special education populations. In D.P.Flanagan, J.L. Genshaft, \& P.L. Harrison (Eds), Contemporary intellectual assessment: theories, tests and issues (pp.457-483). New York: Guilford.

Haney, M.R., \& Evans, J.G. (1999). National survey of school psychologists regarding use of dynamic assessment and other non-traditional assessment techniques. Psychology in the Schools, 36, 295-304.

Gillam, R., \& McFadden, T.U. (1994). Redefining assessment as a holistic discovery process. Journal of Childhood Communication Disorders, 16, 36-40.

Gredler, G.R. (1988). Assessment of learning ability: a current appraisal. In R.M. Gupta, \& P.Coxhead (Eds), Cultural diversity and learning efficiency: recent developments in assessment (pp.39-63). New York: St Martin's Press.

Greenberg, K.H. (2000). Inside professional practice: a collaborative, systems orientation to linking dynamic assessment and intervention. In C. Lidz, \& J.G. Elliott (Eds), Dynamic assessment: prevailing models and applications (pp.489-519). New York: Elsevier.

Greenfield, S. (1997). The human brain: a guided tour. London: Weidenfeld and Nicolson.

Grigorenko, E.L., \& Sternberg, R.J. (1998). Dynamic Testing. Psychological Bulletin, 124, 75-111.

Gupta, R.M., \& Coxhead, P.(1988a). Introduction. In R.M. Gupta, \& P.Coxhead (Eds), Cultural diversity 
and learning efficiency: recent developments in assessment (pp.xii-xvii). New York: St Martin's Press.

Gupta, R.M., \& Coxhead, P. (1988b). Why assess learning potential? In R.M. Gupta, \& P.Coxhead (Eds), Cultural diversity and learning efficiency: recent developments in assessment (pp.1-21). New York: St Martin's Press.

Guthke, J. (1993). Developments in learning potential assessment. In J.H.M. Hamers, K. Sijtsma, \& A.J.J.M. Ruijssenaars (Eds), Learning Potential assessment: theoretical, methodological and practical issues (pp.43-67). Amsterdam: Swets \& Zeitlinger.

Hamers, J.H.M., \& Resing, W.C.M. (1993). Learning potential assessment: introduction. In J.H.M. Hamers, K. Sijtsma, \& A.J.J.M. Ruijssenaars (Eds), Learning Potential assessment: theoretical, methodological and practical issues (pp.23-41). Amsterdam: Swets \& Zeitlinger.

Herbst, I., \& Huysamen, G.K. (2000). The construction and validation of developmental scales for environmentally disadvantaged preschool children. South African Journal of Psychology, 30, 19-24.

Hessels, M.G.P. (1996). Ethnic differences in learning potential test scores: research into item and test bias in the learning potential test for ethnic minorities. Journal of Cognitive Education, 5, 133-153.

Hessels, M.G.P., \& Hamers, J.H.M. (1993). The learning potential test for ethnic minorities. In J.H.M. Hamers, K. Sijtsma, \& A.J.J.M. Ruijssenaars (Eds), Learning Potential assessment: theoretical, methodological and practical issues (pp.285-311). Amsterdam: Swets \& Zeitlinger.

Jensen, M.R. (2000). The mindladder model: using dynamic assessment to help students learn to assemble and use knowledge. In C.S. Lidz, \& J.G. Elliott (Eds), Dynamic assessment: prevailing models and applications (pp.187-227). New York: Elsevier.

Kirkwood,M.W., Weiler, M.D., Bernstein, J.H., Forbes, P.W., \& Waber, D.P. (2001). Sources of poor performance on the Rey-Osterrieth complex figure test among children with learning difficulties: a dynamic assessment approach. Clinical Neuropsychologist, 15, 345-356.

Kirschenbaum, R.J. (1998). Dynamic assessment and its use with underserved gifted and talented populations. Gifted Child Quarterly, 42, 140-147.

Kliegl, R., Smith, J., \& Baltes, P.B. (1989). Testing-the-limits and the study of adult age differences in cognitive plasticity of a mnemonic skill. Developmental Psychology, 25, 247-256.

Lidz, C.S. (Ed.). (1987). Dynamic assessment: An interactional approach to evaluating learning potential. New York: The Guilford Press.

Lidz, C.S. (1992a). The extent of incorporation of dynamic assessment into cognitive assessment courses: a national survey of school psychology trainers. Journal of Special Education, 26, 325-331.

Lidz, C.S. (1992b). Dynamic assessment: some thoughts on the model, the medium, and the message. Learning and Individual Differences, 4, 125-136.

Lidz, C.S. (1997). Dynamic assessment approaches. In D.P.Flanagan, J.L. Genshaft, \& P.L Harrison (Eds), Contemporary intellectual assessment: theories, tests and issues (pp.281-296). New York: Guilford Press.

Lidz, C.S., \& Pena, E.D. (1996). Dynamic assessment: the model, its relevance as a nonbiased approach, and its application to Latino American preschool children. Language, Speech and Hearing Services in Schools, 27, 367-372.

Meyers, J. (1987). The training of dynamic assessors. In C.S. Lidz (Ed.), Dynamic assessment: an interactional approach to evaluating learning potential (pp.403-425). New York: Guilford Press.

Minick, N. (1987). Implications of Vygotsky's theories for dynamic assessment. In C.S. Lidz (Ed.), Dynamic assessment: an interactional approach to evaluating learning potential (pp.116-140). New York: The Guilford Press.

Murphy, R. (2002). A review of South African research in the field of dynamic assessment. Unpublished Master's dissertation, University of Pretoria. http://upetd.up.ac.za/thesis/available/etd-05042002-161239/).

Murphy, R. (2007). Exploring a meta-theoretical framework for dynamic assessment and intelligence. Unpublished $\mathrm{PhD}$ thesis. University of Pretoria. http://upetd.up.ac.za/thesis/available/etd-09302007-162044/).

Murphy, R. (2008). Dynamic assessment precursors: Soviet ideology and Vygotsky. The Irish Journal of Psychology, 29, 193-233.

Murphy, R., \& Maree, D.J.F. (2006a). A review of South African research in the field of dynamic assessment. South African Journal of Psychology, 36, 1038-1061.

Murphy, R., \& Maree, D.J.F. (2006b). Meta-analysis of dynamic assessment research in South Africa. 
Journal of Cognitive Education and Psychology, 6, 32-60.

Norris, C.J., \& Foxcroft, C.D. (1996). Cognitive maturity and the questioning strategies used by learning disabled and normal subjects: a comparative study. South African Journal of Psychology, 26, 243-247.

Raftery, B., \& Murphy, R. (2009). Awareness of dynamic assessment in Ireland: a preliminary survey. Unpublished manuscript.

Resing, W.C.M. (1993). Measuring inductive reasoning skills: the construction of a learning potential test. In J.H.M. Hamers, K. Sijtsma, \& A.J.J.M. Ruijssenaars (Eds), Learning Potential assessment: theoretical, methodological and practical issues (pp.219-242). Amsterdam: Swets \& Zeitlinger.

Resing, W.C.M. (1997). Learning potential assessment: the alternative for measuring intelligence? Educational and Child Psychology, 14, 68-82.

Sewell, T.E. (1987). Dynamic assessment as a non-discriminatory procedure. In C.S. Lidz (Ed.), Dynamic assessment: an interactional approach to evaluating learning potential (pp.426-443). New York: The Guilford Press.

Skuy, M.S., Gewer, A., Osrin, Y., Khunou, D., Fridjon, P., \& Rushton, J.P. (2002). Effects of mediated learning experience on Raven's Matrices scores of African and non-African university students in South Africa. Intelligence, 30, 221-232.

Slenders, A.P.A.C., \& Resing, W.C.M. (1997). Leerpotentieelenonderzoek bij allochtone leerlingen: een verkenning met De leerpotentieeltest voor inductief redeneren. Pedagogische Studiën, 74, 183-196.

Sternberg, R.J. (2000). Group and individual differences in intelligence: what can and should we do about them? In A. Kozulin, \& Y. Rand (Eds), Experience of mediated learning: an impact of Feuerstein's theory in education and psychology (pp.55-82). Amsterdam: Pergamon.

Sternberg, R.J., \& Grigorenko, E.L. (2002). Dynamic Testing: the nature and measurement of learning potential. Cambridge: Cambridge University Press.

Strauss, A., \& Corbin, J. (1998). Basics of qualitative research: techniques and procedures for developing grounded theory. London: Sage.

Taylor, T.R. (1994). A review of three approaches to cognitive assessment, and a proposed integrated approach based on a unifying theoretical framework. South African Journal of Psychology, 24, 184-194.

Van de Vijver, F.J.R. (1993). Learning potential assessment from a cross-cultural perspective. In J.H.M. Hamers, K. Sijtsma, \& A.J.J.M. Ruijssenaars (Eds), Learning Potential assessment: theoretical, methodological and practical issues (pp.313-340). Amsterdam: Swets \& Zeitlinger.

Whitley, B.E. (2002). Principles of research in behavioural science. Boston: McGraw Hill.

Wiedl. K.H. (2003). Dynamic testing: a comprehensive model and current fields of application. Journal of Cognitive Education and Psychology, 3, 93-119. 